\title{
Can the Rich Subsidize the Poor?
}

\author{
Kexin Wang \\ Jianghan University, Wuhan, China
}

\begin{abstract}
In the book Intermediate Microeconomics: A Modern Approach, the author Varian (2016) mentioned the benevolent subsidy of the rich people to the poor people in the 19th century in England when discussing the equilibrium problem, and drew the conclusion that this kind of subsidy cannot reach the expected result since if the demand and supply for the cereals of the rich people remain unchanged, the quantity of the cereals that the poor people consumed remains unchanged, thus the equilibrium price that the poor people faced should be determined totally by their own demand curve, and the equilibrium price remains the same no matter how many the cereals are provided to the poor. This article through a further step analysis of this policy, especially explains the policy in a different way, probing into the possibility of the realization of the success of the policy and drawing the conclusion that the success of the policy is possible as long as it is in a suitable circumstance.
\end{abstract}

Keywords: equilibrium price, demand, supply, consumer surplus, competitive market, monopoly

\section{Review the Classics}

In Varian's (2016) Intermediate Microeconomics: A Modern Approach, when discussing the problem of equilibrium, he mentioned an example: In the 19th century of England, when meeting the bad harvest year, the rich people bought all the yield, and after consuming a specific number of the cereals, sold the leftover to the poor people at half of the price when they purchased them, which was in order to provide charitable help for the poor people.

However, the author pointed out in the following exposition that if we set $\mathrm{D}(\mathrm{p})$ as the demand curve of the poor people, $\mathrm{K}$ as the demand quantity of the rich people, $\mathrm{S}$ as the fixed demand quantity in the bad harvest year. Hypothesized that the supply of the cereals and the demand for the cereals of the rich people are fixed, the equilibrium price before the subsidies from the rich people should be determined by the aggregate demand and the aggregate supply, which is set as:

$\mathrm{D}(\mathrm{p})+\mathrm{K}=\mathrm{S}$

When the rich people provide subsidies, the equilibrium price should be determined by the following function:

$\mathrm{D}\left(\mathrm{p}_{1} / 2\right)+\mathrm{K}=\mathrm{S}$

Therefore, when the two functions are established simultaneously, there must be $\mathrm{p}=\mathrm{p}_{1} / 2$, so that $\mathrm{p}_{1}=2 \mathrm{p}$, which means that at this time the market price is exactly twice as before, thus the author came to the conclusion that this kind of policy did not give the poor people any improvement-they paid just the same price as they paid before.

Kexin Wang, lecturer, School of Business, Jianghan University, Wuhan, China.

Correspondence concerning this article should be addressed to Kexin Wang, the Economic and Technological Development Zone of Wuhan, Jianghan University, Wuhan, China. 


\section{A New Perspective}

In fact, this conclusion came with a prerequisite that the two equations above should be established simultaneously. But if we think about this question from another's point of view, the conclusion may be different:

First, we still hypothesize the equilibrium condition before the subsidies are correct, which is:

$\mathrm{D}(\mathrm{p})+\mathrm{K}=\mathrm{S}$

At the same time, we use the following figure to explain:

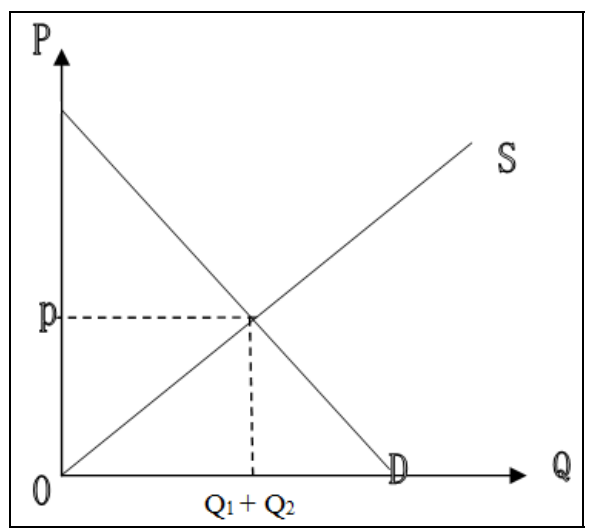

Figure 1. The market equilibrium before subsidy.

In Figure $1 \mathrm{D}$ and $\mathrm{S}$ represent the market demand and supply curve before rich people provided subsidies respectively, the intersection represents the market equilibrium price $\mathrm{p}$ and the market equilibrium demand quantity $\left(\mathrm{Q}_{1}+\mathrm{Q}_{2}\right)$ in this situation, the $\mathrm{Q}_{1}$ represents the demand quantity of the poor people and the $\mathrm{Q}_{2}$ represents the demand quantity of the rich people.

When rich people provide subsidies, since we suppose that the demand quantity of the rich and the poor people does not change, the demand curve of the poor people in Figure 2 should be $D_{1}$, point $A$ means that when the demand quantity is $\mathrm{Q}_{1}$, the price that poor people willing to pay is $\mathrm{p}$, which is the market equilibrium price. Now if other conditions do not change, since from the angle of the supply, the aggregate supply in the market and the demand quantity of the rich people remain unchanged, the poor people face exactly the same supply quantity as before, from the angle of equilibrium price remained at $\mathrm{p}$, which is the opinion of the original text.

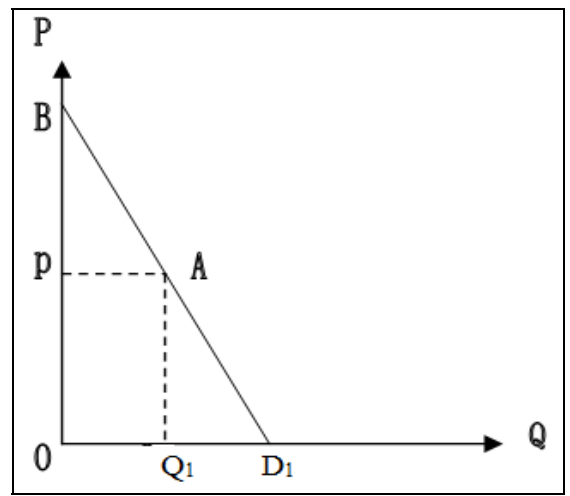

Figure 2. The equilibrium price and quantity of the poor people before subsidy. 
However, if we consider the rich people as a whole, now the supply side situation is more like monopoly, but the monopoly here is not the same as the monopoly that we are familiar with which means that a producer as the only supplier of a product under the condition of facing many demanders can set a relatively high price to obtain the excess profit. Here we mean that the rich people face the same condition where they are the price maker but choose the lower price, and now they set the price as half as the price that they bought from the market originally, which is $\mathrm{p} / 2$.

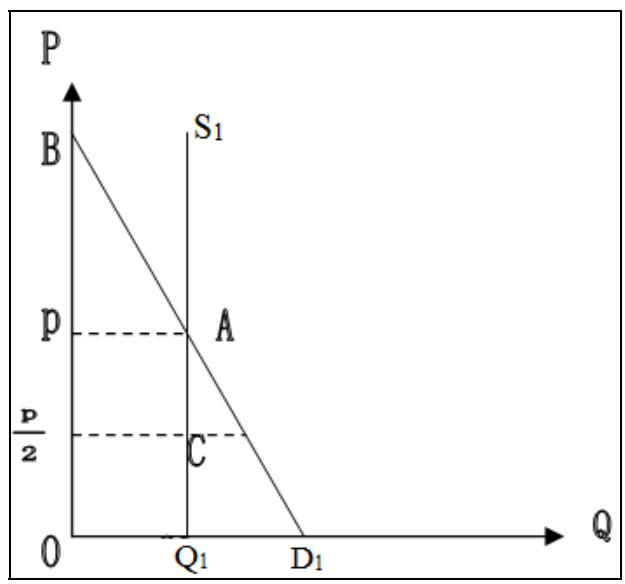

Figure 3. The situation that poor \& rich people faced after subsidy.

Now we can see from Figure 3 that under the original situation, the price that the poor people faced was $\mathrm{p}$ and their demand quantity was still $\mathrm{Q}_{1}$, thus the consumer surplus of the poor people was the area of triangle BPA, whereas when they buy cereals from the rich people at the price of half of the original market, their demand quantity remains unchanged while the price goes down to $p / 2$ now, the consumer surplus is the area of $\mathrm{B}(\mathrm{p} / 2) \mathrm{CA}$, then the increased area of rectangle $\mathrm{PAC}(\mathrm{p} / 2)$ represents the improved scale of the poor people's situation.

On the other hand, now from the point of view of the rich people, the $\mathrm{Q}_{1}$ quantity of cereals that they bought from the market at price $p$ has a total cost of the area of the rectangle $\mathrm{PAQ}_{1} \mathrm{O}$, when they sell the $\mathrm{Q}_{1}$ quantity of cereals to the poor people they set the price at $(\mathrm{p} / 2)$, and now they provide a vertical supply curve which is presented in Figure 3 as $S_{1}$.

We can see that when the rich people sell cereals to the poor people at the price of $\mathrm{p} / 2$, their total revenue is the area of rectangle $(\mathrm{p} / 2) \mathrm{CQ}_{1} \mathrm{O}$, their loss is $\mathrm{PAQ}_{1} \mathrm{O}-(\mathrm{p} / 2) \mathrm{CQ}_{1} \mathrm{O}=\mathrm{PAC}(\mathrm{p} / 2)$, which is exactly the consumer surplus that the poor people gained.

\section{Conclusion}

Therefore, from the analysis above we can see that through the method that in the bad harvest years the rich people buy cereals from the market and then resell them to the poor people at half of the price they paid at the market we can provide charitable help for the poor people as long as the rich people are willing to bear the extra loss from the markdown. In another word, the establishment of Hal R. Varian's point here is conditioned, which is no matter how we distribute the cereals, we always face a perfect competitive market.

\section{References}

Varian, H. R. (2016). Intermediate microeconomics: A modern approach (9th ed.) (p. 212). Gezhi Press. 